\title{
What do Patients Want? The Importance of Patient-reported Outcomes
}

\author{
Hélène Schoemans, Natacha Bolaños, and Lorna Warwick
}

Understanding of what it means for patients to receive CAR-T therapy remains insufficient due to the small number of studies with a quality of life (QOL) focus, selection bias of respondents, high risk of attrition due to disease relapse, and limited length of follow-up. CAR-T therapy is often presented as a last option for patients with advanced disease. The primary aim of the treatment is patient survival and hopefully disease elimination. However, understanding other aspects of health, such as functional status, cognitive function, psychosocial concerns, and other health-related (QOL) issues, is key to appreciating the full impact of such therapies at both the individual and societal levels.

Such information can only be accessed by asking patients and caregivers directly, without going through the filter of a third party, using either patient-reported outcome measures and/or qualitative methods, such as interviews or focus groups. This approach is supported by the cell therapy community, but evidence remains limited (Chakraborty et al. 2019; Shalabi et al. 2021).

Side effects, such as CRS, neurotoxicity, and B-cell aplasia, are well documented. Importantly, many patients report other concerns that impact their well-being and require appropriate support from their health care team (Bamigbola et al. 2021).

\author{
H. Schoemans $(\square)$ \\ Department of Hematology, University Hospitals Leuven, Leuven, Belgium \\ Department of Public Health and Primary Care, ACCENT VV, Katholieke Universiteit \\ Leuven - University of Leuven, Leuven, Belgium \\ e-mail: helene.schoemans@uzleuven.be \\ N. Bolaños \\ Lymphoma Coalition, Madrid, Spain \\ e-mail: natachab@lymphomacoalition.org \\ L. Warwick \\ Lymphoma Coalition, Management, Mississauga, ON, Canada \\ e-mail: lorna@lymphomacoalition.org


Hoogland and colleagues recently showed that over half of adult CAR-T recipients complained of moderate to severe fatigue (84\%), decreased appetite $(73 \%)$, dry mouth (61\%), and insomnia (55\%) in the first 100 days following therapy, with a symptom peak seen after approximately two weeks (Hoogland et al. 2021). Compared to baseline, physical functioning significantly improved, with decreased pain, fatigue, and depression, but anxiety increased (Hoogland et al. 2021). In a follow-up study up to 1-year post-CAR-T cell infusion, approximately one-third of patients presented lasting moderate to severe fatigue and insomnia, and 20\% had decreased memory compared to baseline (Barata et al. 2021). In contrast, in children and adolescents (3-21 years) who had undergone CAR-T therapy for acute leukaemia, a steady significant improvement in QOL compared to baseline was seen from 3 months post-treatment in all domains examined (Laetsch et al. 2019).

Mental health is a long-term issue, considering that up to $20 \%$ of 1 to 5 -year adult survivors reported clinically meaningful depression or anxiety and over onethird experienced cognitive difficulties (Ruark et al. 2020). Marziaz and colleagues also showed meaningful improvement in QOL up to month 18 in all domains, except for mental health (Maziarz et al. 2020). Of note, there have been no significant associations identified between the severity of CRS or ICANS and long-term quality of life to date.

Little is known about patient priorities and needs after CAR-T therapy, but the current literature underscores the importance of appropriate information. By interviewing patients, Matthews et al. found that most felt unprepared for the emotional aspects of CAR-T therapy nor were they prepared for the intensity of the toxicities (Matthews et al. 2019). The importance of addressing issues, such as clear information on the treatment trajectory (Bamigbola et al. 2021), financial toxicity, and the importance of family members and other caregivers, has also been described (Foster et al. 2020).

Future studies are needed to broaden the understanding of CAR-T cell therapy survivorship to identify the themes most important to patients, potentially including themes identified in other cell therapy recipients, such as impact on informal caregivers, return to school/work, financial issues, and access to care (Burns et al. 2018). Outcome evaluation in large groups of patients with extended longitudinal followup is particularly important to identify predictors of QOL, specifically of mental health and cognitive function, so patients undergoing CAR-T therapy can be better informed and supported.

\section{Key Points}

- Symptom burden generally decreases over time, starting from 3 months post CAR-T therapy.

- Mental health and cognitive function remain a concern in long-term survivors.

- Currently, there is no indication of an association between CRS or ICANs and long-term QOL.

- Patient priorities, expectations, and needs regarding CAR-T cell therapy urgently need to be assessed. 


\section{References}

Bamigbola O, Dren N, Warwick L. Cross-sectional study of the side-effects profile and patientdoctor communication about side effects in patients with lymphoma treated with CAR-T therapy. Poster presented at: 3rd European CAR-T -cell Meeting 2021, Virtual, 2021.

Barata A, Hoogland AI, Hyland K, Kommalapati A, Irizarry-Arroyo N, Rodriguez Y, et al. Patientreported toxicities in axicabtagene ciloleucel recipients: 1-year follow-up. Transplant Cell Ther. 2021;27(3):375.

Burns LJ, Abbetti B, Arnold SD, Bender J, Doughtie S, El-Jawahiri A, et al. Engaging patients in setting a patient-centered outcomes research agenda in hematopoietic cell transplantation. Biol Blood Marrow Transplant. 2018;24(6):1111-8.

Chakraborty R, Sidana S, Shah GL, Scordo M, Hamilton BK, Majhail NS. Patient-reported outcomes with chimeric antigen receptor T cell therapy: challenges and opportunities. Biol Blood Marrow Transplant. 2019;25(5):155-62.

Foster M, Fergusson DA, Hawrysh T, Presseau J, Kekre N, Schwartz S, et al. Partnering with patients to get better outcomes with chimeric antigen receptor T-cell therapy: towards engagement of patients in early phase trials. Res Involve Engage. 2020;6:61.

Hoogland AI, Jayani RV, Collier A, Irizarry-Arroyo N, Rodriguez Y, Jain MD, et al. Acute patientreported outcomes in B-cell malignancies treated with axicabtagene ciloleucel. Cancer Med. 2021;10(6):1936-43.

Laetsch TW, Myers GD, Baruchel A, Dietz AC, Pulsipher MA, Bittencourt H, et al. Patient-reported quality of life after tisagenlecleucel infusion in children and young adults with relapsed or refractory B-cell acute lymphoblastic leukaemia: a global, single-arm, phase 2 trial. Lancet. 2019;20(12):1710-8.

Matthews A, Sidana S, Seymour L, Pick N, Pringnitz J, Argue D, et al. QIM19-136: developing an Ideal CAR-T cell therapy patient experience through human-centered design and innovation. J Natl Compr Cancer Netw. 2019;17:3-5.

Maziarz RT, Waller EK, Jaeger U, Fleury I, McGuirk J, Holte H, et al. Patient-reported longterm quality of life after tisagenlecleucel in relapsed/refractory diffuse large B-cell lymphoma. Blood Adv. 2020;4(4):629-37.

Ruark J, Mullane E, Cleary N, Cordeiro A, Bezerra ED, Wu V, et al. Patient-reported neuropsychiatric outcomes of long-term survivors after chimeric antigen receptor T cell therapy. Biol Blood Marrow Transplant. 2020;26(1):34-43.

Shalabi H, Gust J, Taraseviciute A, Wolters PL, Leahy AB, Sandi C, et al. Beyond the storm - subacute toxicities and late effects in children receiving CAR-T cells. Clin Oncol. 2021;18(6):363-78.

Open Access This chapter is licensed under the terms of the Creative Commons Attribution 4.0 International License (http://creativecommons.org/licenses/by/4.0/), which permits use, sharing, adaptation, distribution and reproduction in any medium or format, as long as you give appropriate credit to the original author(s) and the source, provide a link to the Creative Commons license and indicate if changes were made.

The images or other third party material in this chapter are included in the chapter's Creative Commons license, unless indicated otherwise in a credit line to the material. If material is not included in the chapter's Creative Commons license and your intended use is not permitted by statutory regulation or exceeds the permitted use, you will need to obtain permission directly from the copyright holder. 